\title{
Factors Affecting the Perception of Family Functioning among Couples in Child-Rearing Japanese Families
}

\author{
Junko Honda', Yuuri Nakai², Shota Kakazu${ }^{1}$, Naohiro Hohashi ${ }^{*}$ \\ ${ }^{1}$ Division of Family Health Care Nursing, Department of Nursing, Graduate School of Health Sciences, Kobe \\ University, Hyogo, Japan \\ ${ }^{2}$ Department of Nursing, Faculty of Health Sciences, School of Medicine, Kobe University, Hyogo, Japan \\ Email: junko@gold.kobe-u.ac.jp, ${ }^{*}$ naohiro@hohashi.org
}

Received 12 April 2015; accepted 6 May 2015; published 7 May 2015

Copyright (C) 2015 by authors and Scientific Research Publishing Inc.

This work is licensed under the Creative Commons Attribution International License (CC BY). http://creativecommons.org/licenses/by/4.0/

(c) (i) Open Access

\begin{abstract}
In family healthcare nursing, the family system unit (i.e., a group in which the members, seen as a whole, mutually interact) is the target of care. As nurses tend to obtain family-related information from particular family members in the clinical setting, when assessing families, they often confront the issue of the differences between the theoretical level and methodological level. Although this issue needs resolving for evidence-based family nursing practice, sufficient research is lacking on the methodology related to family assessment. The present study aimed to clarify the factors that affected evaluation of family functioning among couples. Semi-structured interviews were conducted with 10 child-rearing families (couples) using the Survey of Family Environment (SFE) as a family functioning scale. Content analysis identified 12 factors that affected discrepancies in the couples' evaluations and eight factors that affected agreement in those evaluations. These factors were classified into three categories: factors concerning family or family members; factors concerning questions related to the SFE; and factors concerning the view of the family as a whole. The results of this study should contribute to the development of family assessment tools and effective methods for evaluation of family care.
\end{abstract}

\section{Keywords}

Family Functioning, Discrepancy, Survey of Family Environment (SFE), Japan, Concentric Sphere Family Environment Theory (CSFET)

\footnotetext{
${ }^{*}$ Corresponding author.
}

How to cite this paper: Honda, J., Nakai, Y., Kakazu, S. and Hohashi, N. (2015) Factors Affecting the Perception of Family Functioning among Couples in Child-Rearing Japanese Families. Open Journal of Nursing, 5, 407-415. 


\section{Introduction}

In recent decades, various theories and models for family nursing have been developed around the world [1]. For patients who suffer from a chronic condition or disability, the family plays a major role. It has been noted that the functioning of modern families in Japan has become weaker because of the trend toward nuclear families, many with dual incomes: the decline in the number of children; its super-aging society; and factors that have led to increases in divorce and domestic violence. Family nursing practice with prophylactic perspective will increasingly be required to deal with potential and future family problems [2]. Family nursing practices and studies that focus not only on patients but also on their families have been increasing. It is essential to accumulate evidence about family nursing care toward developing family nursing skills and building family nursing expertise. Previous evaluation methods have generally focused on individual family members; however, such approaches are insufficient in examining the effectiveness of overall family intervention since they do not assess the family as a whole. What is required is a methodological approach that evaluates the whole family. Although various family assessment scales have been developed, those respondents are individual family members [3]. Even if all family members respond to a questionnaire, the responses will inevitably be made at the individual level. To develop evaluation methods that address the whole family, it is necessary to explore the reasons for any discrepancies that may occur among the various family members.

One study has identified the relation between perception gaps among family members and problematic behaviors [4]. Those authors determined that perception gaps in a family may lead to problems such as suicide. The presence of perception gaps among family members, even though it would appear that they evaluated the same family phenomenon, is likely to indicate family problems. For these reasons, the factors that lead to discrepancies in evaluation among family members need to be clarified.

The purpose of the present study was to examine the factors that affect a couple's evaluation of family functioning and to contribute toward the development of an evaluation method for assessing a family as a whole (family system unit).

\section{Methods}

\subsection{Participants and Procedure}

The participants of this study were families with children at the elementary to high school level. Family functioning depends on the growth and development sectors for the family system unit [5]. Accordingly, this study was limited to child-rearing families so as to control the effect of growth and development for the family system unit with respect to family functioning score.

The study participants resided in one of two selected prefectures in Japan. With the support of local boards of education and school principals, request forms for study participation, which included details of the purpose of the study, were distributed to certain families. Using telephone, fax, or e-mail, interviewers directly contacted families that consented to participate and arranged a date and place for an interview. The participants consisted of 10 families (10 couples): one family with a high-school student, two families with junior high-school students, and seven families with elementary school students.

\subsubsection{Operational Definitions of Basic Terms}

"Family" was defined as a unit group as a system of the sum (OR operation) of individuals (i.e., living people) who are recognized as belonging to the group by other constituent member(s). Families were thus comprised of parents, spouses (including cohabitation, common-law marriage, and de facto marriage), children, and othersirrespective of whether the members were living together. "Children" referred to all family members under 18 years old. These terms were explained on the first page of the instructions for completing the SFE.

"Family functioning" was defined as family's cognitive activities performed by a family and its abilities to act on the family environment through individual family members' role-related behavior. The current level of family functioning was measured according to the degree of satisfaction by means of the SFE-as perceived by the family system unit.

\subsubsection{Data Collection}

To assess the holistic family environment, semi-structured interviews were conducted using the Family Envi- 
ronment Assessment Model (FEAM) based on the Concentric Sphere Family Environment Theory/Model (CSFET/M) [6]. The Family Environment Map (FEM) and SFE, which are family assessment tools of FEAM, were used to guide the interviews.

The interviews were held in the family home or in a room at our institution that ensured privacy. The couples responded on an individual basis to the SFE after they had signed the consent forms. The difference between the husband's score and wife's score was then calculated.

The SFE scores were divided into two categories: large score discrepancy (2 - 4 points) or small score discrepancy ( 0 - 1 point), and interviewers asked the couples to discuss their evaluations. The interviewers asked the participants how they interpreted each question and answer and the couples discussed the reasons for their evaluation having been in agreement or not. Though a 2-point difference in the SFE score among couples was regarded as a discrepancy, this did not constitute a statistically significant difference.

\subsection{Instruments}

\subsubsection{Survey of Family Environment (SFE)}

Based on the CSFET/M [6], the SFE is a 30-item self-administered instrument that assesses five domains (supra system, macro system, micro system, family internal environment system, and chrono system) of family functioning [7]. Table 1 presents the 30-item questions. The SFE is structured to allow the family to be evaluated as a whole as it depends not on the individual family member's perception, but the family's perception of itself as a unit, to achieve lower discrepancy among family members. To avoid disparities in family functioning scores among individual family members, instructions were written to the effect that the respondents should evaluate the satisfaction level for each item based not on their perception as individual family members, but on their perception as a family unit.

The SFE contains two questions relating to family satisfaction and family importance. Each of these items generates a satisfaction score (SS) and importance score (IS). Each of these is rated from 1 to 5 points, with a higher SS indicating a higher level of family functioning. The SFE has been subjected to rigorous reliability and validity investigations using paired partners in 1990 child-rearing families [7]. The internal consistency reliability has been found to be satisfactory, with a Cronbach's alpha of at least 0.93 ; test-retest reliability over a 2-week interval was established. Concurrent validity was demonstrated by means of significant correlations with the Japanese version of the Feetham Family Functioning Survey (FFFS) [8]. Construct validity was supported by a confirmatory factor analysis of a five-factor structure based on the CSFET/M.

\subsubsection{Family Environment Map (FEM)}

The Family Environment Map (FEM) is a relationship map of a target family: an assessment tool to visualize a whole image, mainly drawing the human family internal environment. This assessment tool indicates such details as a target family's formation (family structure and kin structure), the relationship among family members, the presence of an interface membrane (range of the family), and the interaction between the family and its external environment, using lines and symbols [5]. The FEM was used to determine family attributes in this study.

\subsection{Data Analysis and Rigor}

The data from the semi-structured interviews were analyzed using inductive content analysis methods [9]; that process included open coding, the creation of subcategories and categories, and abstraction. Researchers read the interview transcripts multiple times; focused on the factors affecting evaluation of family functioning that emerged from evaluation of the content; and coded them with labeling names. The codes were modified and grouped them into subcategories and categories based on their semantic relationships. To ensure analytical rigor, all four researchers undertook this analytic process.

\subsection{Ethical Approval}

Ethical approval for this study was obtained from the Institutional Review Board of Kobe University. All participants received both an oral and written explanation that included details of the study purpose and methods, privacy protection, and publication of the study results. The interviews were conducted after obtaining informed consent. 
Table 1. Survey of Family Environment (SFE).

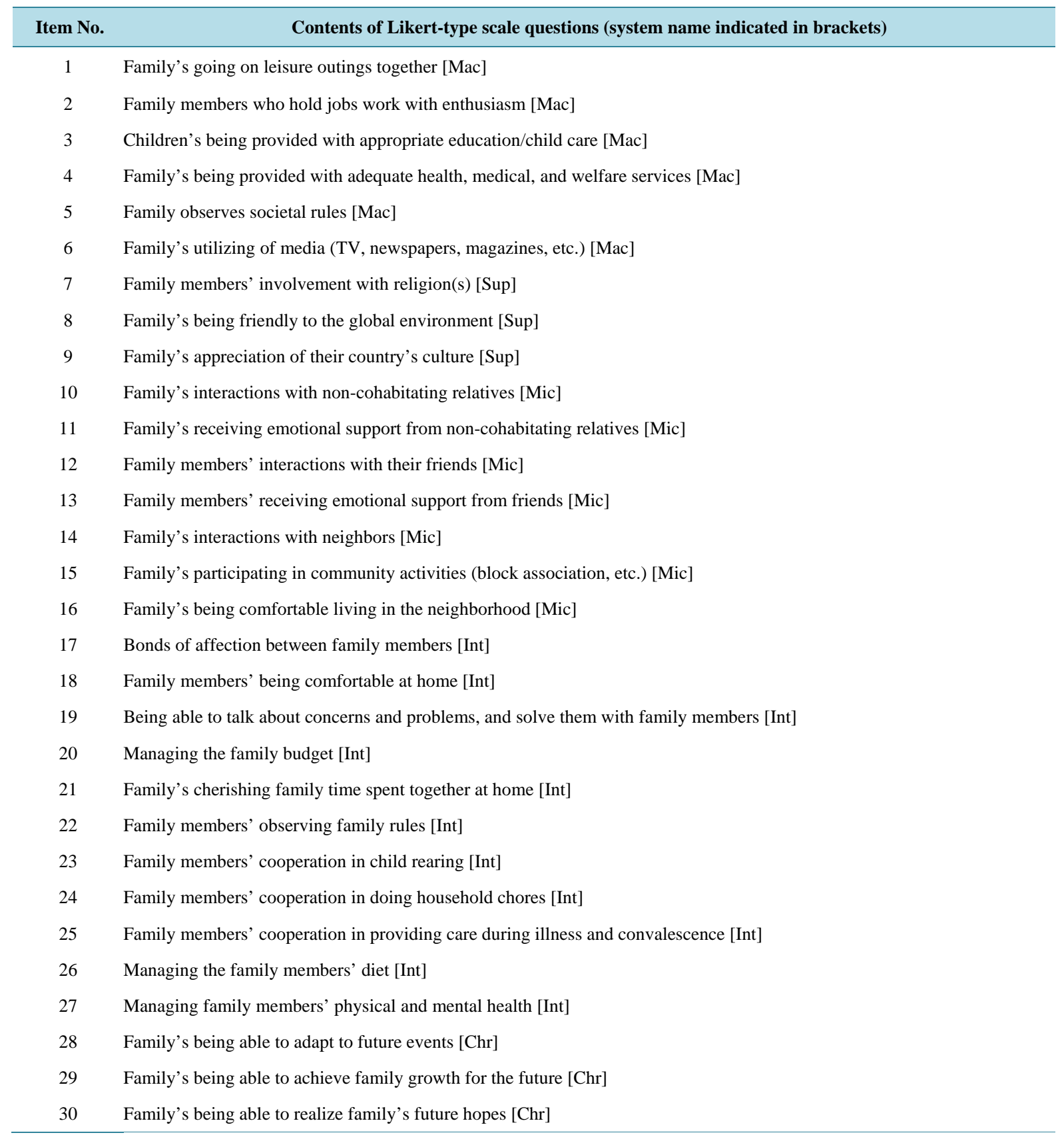

Note: Sup = supra system; Mac = macro system; Mic = micro system; Int = family internal environment system; Chr = chrono system. Items number 2, 3, 23 and 25 contain a box where INAP (inapplicable) may be selected.

\section{Results}

\subsection{Sample Demographics}

The sample demographics appear in Table 2. The mean age for adult males was 45.1 (standard deviation $[\mathrm{SD}]=5.1)$ years; for adult females, $42.1(\mathrm{SD}=5.5)$ years; and children, $12.0(\mathrm{SD}=3.8)$ years. The mean number of family members was $4.4(\mathrm{SD}=1.0)$ and that of children only was $2.4(\mathrm{SD}=1.0)$. All the study participants belonged to nuclear families. The mean required time for an interview was $91.5(\mathrm{SD}=8.6) \mathrm{mi}-$ nutes. 
Table 2. Data on family demographic characteristics of participant families.

\begin{tabular}{|c|c|c|c|c|c|c|c|}
\hline $\begin{array}{l}\text { Family } \\
\text { ID }\end{array}$ & $\begin{array}{l}\text { Husband's } \\
\text { age }\end{array}$ & $\begin{array}{l}\text { Wife's } \\
\text { age }\end{array}$ & $\begin{array}{l}\text { Mean age of } \\
\text { children }\end{array}$ & $\begin{array}{l}\text { Number of } \\
\text { children }\end{array}$ & $\begin{array}{l}\text { Husband } \\
\text { employed }\end{array}$ & $\begin{array}{c}\text { Wife } \\
\text { employed }\end{array}$ & $\begin{array}{l}\text { Family member with } \\
\text { a disease/illness }\end{array}$ \\
\hline 1 & 50 & 47 & 11.5 & 2 & Yes & No & No \\
\hline 2 & 42 & 41 & 13.5 & 2 & Yes & Yes & No \\
\hline 3 & 47 & 42 & 15.5 & 2 & Yes & Yes & No \\
\hline 4 & 44 & 42 & 12.0 & 3 & Yes & Yes & No \\
\hline 5 & 38 & 32 & 9.0 & 1 & Yes & No & No \\
\hline 6 & 53 & 48 & 8.5 & 2 & Yes & No & No \\
\hline 7 & 41 & 39 & 8.7 & 3 & Yes & Yes & Yes (atopic dermatitis) \\
\hline 8 & 38 & 34 & 6.5 & 2 & Yes & Yes & No \\
\hline 9 & 51 & 48 & 15.0 & 5 & Yes & Yes & Yes (asthma) \\
\hline 10 & 47 & 48 & 15.0 & 2 & Yes & Yes & No \\
\hline
\end{tabular}

\subsection{Factors Affecting Discrepancies in Evaluations of Family Functioning Score}

The factors that affected discrepancies in evaluations of the family functioning score among the couples are presented in Table 3. Three categories and 12 subcategories were extracted. The three categories were: factors concerning family or family members; factors concerning questions related to the SFE; and factors concerning the view of the family as a whole. Below, the subcategories are indicated in italics, and the data appear within quotation marks.

\subsubsection{Factors Concerning Family or Family Members}

Some participants expressed that incompatibility of temperament within the family was the reason for their scores not agreeing with those of their spouses: "We think differently. His personality is different from mine. He is nervous and meticulous, and so he is not satisfied unless everything is perfect"; "Because we have different personalities."

Age and the environments in which the participants had grown up differed within families, i.e., having a different family background as a child circumstance was one of the factors. "My wife usually does it. I'm also involved in it, but I don't think deeply about it. She cares about the details." Since wives usually assume the role of cooking for families, they are more concerned about dietary matters than their husbands; thus, playing different family roles was cited as one of the factors here. In addition, influence of the family member's own wishes and family member's personal experiences were also cited as factors.

\subsubsection{Factors Concerning Questions Related to the SFE}

Factors concerning questions related to the SFE were as follows: Use of abstract questions, the question related to irregular situations for the family member, different understanding of the question by the family member, difference in the degree of importance that the family member accords to the question, and different evaluation standards by the family member. Participants expressed their thoughts related to questions as follows: "I think the questions are very vague. They are too difficult to answer"; "I am not sure whether I should write concerning my wishes or the actual situation"; "I didn't read the instructions of the SFE properly"; "It is too difficult to choose the score of 5 , which could mean $90 \%$ or $80 \%$."

\subsubsection{Factors Concerning the View of the Family as a Whole}

One response was as follows: "I think that my family includes my grandmothers." The SFE requires that the respondents provide their perception of the family as a whole, and so different perception of the family range by family members was evident. The other factor related to the view of the family as a whole was different relationships among the family members as exemplified by the following: "I think my husband doesn't realize it, but I really want to see my own relatives." 
Table 3. Factors affecting discrepancies in evaluation of family functioning score among couples.

\begin{tabular}{ll}
\hline Categories & Subcategories \\
\hline & $\begin{array}{l}\text { Incompatibility of temperament within the family } \\
\text { Having a different family background as a child circumstance } \\
\text { Factors concerning family or family } \\
\text { members }\end{array}$ \\
& $\begin{array}{l}\text { Playing different family roles } \\
\text { Influence of the family member's own wishes }\end{array}$ \\
& Family member's personal experiences \\
\hline Factors concerning questions related to & $\begin{array}{l}\text { The question related to irregular situations for the family member } \\
\text { the SFE }\end{array}$ \\
& $\begin{array}{l}\text { Different understanding of the question by the family member } \\
\text { Difference in the degree of importance that the family member accords to the question } \\
\text { Different evaluation standards by the family member }\end{array}$ \\
\hline $\begin{array}{l}\text { Factors concerning the view of the } \\
\text { family as a whole }\end{array}$ & $\begin{array}{l}\text { Different perception of the family range by the family members } \\
\text { Different relationships among the family members }\end{array}$ \\
\hline
\end{tabular}

\subsection{Factors Affecting Unanimous Evaluation of Family Functioning Score}

The factors that affected unanimous evaluation of the family functioning score among the couples appear in Table 4. Three categories and eight subcategories were extracted. The three categories were the same as those for factors affecting discrepancies in the evaluation: factors concerning family or family members; factors concerning questions related to the SFE; and factors concerning the view of the family as a whole. Below, the subcategories are indicated in italics, and the data appear in quotation marks.

\subsubsection{Factors Concerning Family or Family Members}

One response was as follows: "We spend a lot of time together and talk to each other a good deal. We know each other's daily lives and understand each other." This related to good communication within the family and spending a lot of time with the family: these are related to factors affecting unanimous evaluation within the family. Other factors were sharing values within the family and sharing opinions within the family. These are exemplified by the following responses: "If you are a couple, you have similar characteristics. We got married because we share the same values"; "We are of the same mind."

\subsubsection{Factors Concerning Questions Related to the SFE}

One of the subcategories here was questions concerning predictable events in the near future. An example of a response in this subcategory was as follows: "It's in my pocket. Our parents are getting older, we have to care for them as necessary." One response indicated that the family was concerned about working together for the sake of the global environment: "Our family is constantly concerned about not just throwing trash away. We segregate our waste for recycling at home.” This is represented by the subcategory questions concerning the situations in which all family members are in agreement. The subcategory questions concerning the situations that all family members have already experienced was reflected in the following response: "We like going out. When we go out, we always go out together, adjusting our schedules as necessary. I think we're reasonably satisfied with that."

\subsubsection{Factors Concerning the View of the Family as a Whole}

No discrepancies were observed in a couple's family functioning scores if the family member was able to assess the general opinion within the family: "I think that money is very important. But I don't believe that my family thinks the same way as me. I realize that my own beliefs in some areas may be stronger than those of the other family members." One subcategory here was ability to assess the current situation related to the family as a whole. 
Table 4. Factors affecting unanimous evaluation of family functioning score among couples.

\begin{tabular}{|c|c|}
\hline Categories & Subcategories \\
\hline \multirow{4}{*}{ Factors concerning family or family members } & Good communication within the family \\
\hline & Spending a lot of time with the family \\
\hline & Sharing values within the family \\
\hline & Sharing opinions within the family \\
\hline \multirow{3}{*}{ Factors concerning questions related to the SFE } & Questions concerning predictable events in the near future \\
\hline & Questions concerning the situations in which all family members are in agreement \\
\hline & Questions concerning the situations that all family members have already experienced \\
\hline $\begin{array}{l}\text { Factors concerning the view of the family } \\
\text { as a whole }\end{array}$ & Ability to assess the current situation related to the family as a whole \\
\hline
\end{tabular}

\section{Discussion}

The factors that affected the evaluation of the family functioning score consisted of three categories: factors concerning family or family members; factors concerning questions related to the SFE; and factors concerning the view of the family as a whole. Among the factors concerning family or family members were factors that affected discrepancies in evaluation that could be controlled for, and those that could not be controlled. Some of these factors were related to the family internal environment, such as incompatibility of temperament within the family, having a different family background as a child circumstance, and playing different family roles. It may be difficult to control for such factors directly in a research setting.

Some studies have examined the balancing of work and home life and found that the situation in Japan may be more difficult than in other Organization for Economic Co-operation and Development countries. Japanese women tend to play a greater role in domestic tasks, such as caring and housework, than in many other developed countries [10] [11]. The present study also found that couples had different opinions regarding household chores and child rearing: playing different family roles appeared as a discrepancy in the evaluation among couples. Conversely, it is possible that influence of the family member's own wishes and family member's personal experiences could have been compensated for by employing more appropriate instructions with the questionnaire. Since family members are often able to anticipate the responses given by other members to questions relating to various situations, it may have been appropriate to proactively modify the preliminary instructions.

The factors that affected unanimous evaluation, good communication within the family, spending a lot of time with the family, sharing values within the family, and sharing opinions within the family, were a reflection of family strength. The family members were familiar with one another, and they were able to arrive at a similar evaluation because they spent considerable time together and talked to one another a good deal. Lack of communication within the family and insufficient time spent with the family could lead to difficulty in being able to evaluate the view of the family as a whole. One study has found that a couple's own reports differed if the partners suffered from a lack of communication [12]. The present investigation examined similar factors to that previous study as well as additional ones, such as communication within the family, including communication with children, and spending time with the family. Thus, it is necessary for families to be aware that the evaluations of its members may differ with respect to particular family issues [12].

Some of the factors affecting evaluation of family functioning score concerned questions related to the SFE. These factors involved two types: factors particular to the SFE and factors in other family functioning scales. Factors such as, use of abstract questions and different evaluation standards by the family member were not only adopted by the SFE but potentially in other scales as well. As difficult questions decrease the depth of respondents' understanding, respondents may have misunderstood the meanings of such questions. Therefore, when developing a scale, a high degree of caution in sentence composition and word choice is called for, so as to ensure that face validity of the questions is obtained.

The SFE is able to examine the family as a whole, it includes factors concerning the view of an entire family. This suggests the difficulty in making assessments that hypothesize the entire family, and will be one of the future challenges for the SFE. A preceding study [3] using another family functioning scale, the Feetham Family 
Functioning Survey (FFFS) [8], demonstrated that the questionnaire itself contributed to discrepancies between family member's perceptions due to use of certain expressions in questions, particularly the use of "you" or "your." Although the FFFS and SFE work from different perspectives, the result of this study confirmed a preceding study [8] on the issue of the questionnaire itself. It will be necessary to continue to work to minimize the impact of questions upon the scale of the evaluation.

Although this study focused on child-rearing families, a preceding study showed that family characteristics affected the family's perception of family functioning [3]. Further study focused on families with various characteristics is needed because a diverse family environment might lead to other factors affecting evaluation of the family functioning scale. In addition, while all participant families in this study were nuclear families, extended families might tend to have multiple opinions by each family member because of the greater number of constituent members in the family. The present study was significant in its method by which couples are interviewed and able to engage in discussion concerning their evaluation and the factors affecting their response. However, it is believed that these families had good relationships because they participated in the study together and few discrepancies were shown in the evaluations. The study results will provide basic data for family nursing research and contribute to issue resolution for family assessment [2].

\section{Conclusion}

With a focus on child-rearing families, this study examined the factors that affected couples' evaluation of family functioning. Our semi-structured interviews identified the categories of factors as follows: factors concerning family or family members; factors concerning questions related to the SFE; and factors concerning the view of the family as a whole. Twelve subcategories of factors were found to have affected discrepancies in evaluation: Incompatibility of temperament within the family; having a different family background as a child circumstance; playing different family roles; influence of the family member's own wishes; family member's personal experiences; use of abstract questions; the question related to irregular situations for the family member; different understanding of the question by the family member; difference in the degree of importance that the family member accords to the question; different evaluation standards by the family member; different perception of the family range by family members; and different relationships among the family members. The factors that affected unanimous evaluation comprised eight subcategories: Good communication within the family; spending a lot of time with the family; sharing values within the family; sharing opinions within the family; questions concerning predictable events in the near future; questions concerning the situations in which all family members are in agreement; questions concerning the situations that all family members have already experienced; and ability to assess the current situation related to the family as a whole.

\section{Acknowledgements}

The authors would like to express our gratitude to all the study participants. This study was supported in part by a Grant-in-Aid for Exploratory Research from the Japan Society for the Promotion of Science (JSPS) in Japan, granted to the last-named author (Grant nos. 20659349 and 26670981).

\section{Declaration of Conflicting Interests}

The authors declare that they have no potential conflicts of interest with respect to the research, authorship, and/or publication of this article.

\section{References}

[1] Nyirati, C.M., Denham, S.A., Raffle, H. and Ware, L. (2012) Where Is Family in the Family Nurse Practitioner Program? Results of a U.S. Family Nurse Practitioner Program Survey. Journal of Family Nursing, 18, 378-408. http://dx.doi.org/10.1177/1074840712443872

[2] Hohashi, N. and Honda, J. (2010) Kazoku kinou ron [Family Functioning]. In: Hohashi, N., Ed., Atarashii kazoku kangogaku: Riron, jissen, kenkyu [New Family Health Care Nursing: Theory, Practice and Research], Medical Friend, Tokyo, 38-45.

[3] Honda, J. and Hohashi, N. (2015) Discrepancies between Couples’ Perceptions of Family Functioning in Child-Rearing Japanese Families. Nursing and Health Sciences, 17, 57-63. http://dx.doi.org/10.1111/nhs.12148 
[4] Lipschitz, J.M., Yen, S., Weinstock, L.M. and Spirito, A. (2012) Adolescent and Caregiver Perception of Family Functioning: Relation to Suicide Ideation and Attempts. Psychiatry Research, 200, 400-403. http://dx.doi.org/10.1016/j.psychres.2012.07.051

[5] Honda, J. and Hohashi, N. (2014) Development of a New Growth and Development Sectors for the Family System Unit. Proceedings of the 25th International Nursing Research Congress, 822-823.

[6] Hohashi, N. and Honda, J. (2011) Development of the Concentric Sphere Family Environment Model and Companion Tools for Culturally Congruent Family Assessment. Journal of Transcultural Nursing, 22, 350-361. http://dx.doi.org/10.1177/1043659611414200

[7] Hohashi, N. and Honda, J. (2012) Development and Testing of the Survey of Family Environment (SFE): A Novel Instrument to Measure Family Functioning and Needs for Family Support. Journal of Nursing Measurement, 20, 212 229. http://dx.doi.org/10.1891/1061-3749.20.3.212

[8] Hohashi, N., Maeda, M. and Sugishita, C. (2000) Development of the Japanese Language Feetham Family Functioning Survey (FFFS) and Evaluation of Its Effectiveness. Japanese Journal of Research in Family Nursing, 6, 2-10.

[9] Elo, S. and Kyngäs, H. (2008) The Qualitative Content Analysis Process. Journal of Advanced Nursing, 62, 107-115. http://dx.doi.org/10.1111/j.1365-2648.2007.04569.x

[10] Chappell, N.L., Dujela, C. and Smith, A. (2014) Caregiver Well-Being: Intersections of Relationship and Gender. Research on Aging, Published Online.

[11] Mautner, E., Ashida, C., Greimel, E., Lang, U., Kolman, C., Alton, D. and Inoue, W. (2014) Are There Differences in the Health Outcomes of Mothers in Europe and East-Asia? A Cross-Cultural Health Survey. BioMed Research International, Published Online.

[12] Neal, A.G. and Groat, H.T. (1976) Consensus in the Marital Dyad: Couples’ Perceptions of Contraception, Communication, and Family Life. Sociological Focus, 9, 317-329. http://dx.doi.org/10.1080/00380237.1976.10570940 